ISSN : $2620-4665$ (print)

ISSN : $2620-4673$ (online)

Website : http://jurnal.untan.ac.id/index.php/JPLP2KM

\title{
PELATIHAN PENYUSUNAN LAPORAN KEUANGAN DAN PAJAK ENTITAS YANG TIDAK MENYELENGGARAKAN SISTEM AKUNTANSI BAGI GURU SMK DAN SMA PENGAJAR AKUNTANSI DI KOTA PONTIANAK
}

\author{
Susan Andriana1, Zulham Al Farizi 2*, Linda Suherma ${ }^{3}$, Ninik Kurniasih 4, \\ Rika Irawati ${ }^{5}$, Theresia Siwi $\mathrm{K}^{6}$ \\ 1,2,3,4,5,6Politeknik Negeri Pontianak \\ Email: farizi85@gmail.com
}

\begin{abstract}
This activity aims to provide a basic theory of how to compile financial statements for entities that do not hold accounting information systems, provide skills to utilize available technology to conduct financial statement preparation, and introduce the types of information technology used in tax reporting. Currently the industrial world has entered the Industrial era 4.0 graduates from education providers must have technology-based competencies in order to be able to have competitiveness and keep up with the times. Industries that are running domestically, should be able to be carried out and carried out by local workers by increasing their capacity. So that they are not just occupying low positions.
\end{abstract}

Keyword : Financial Statements, Pontianak

\section{PENDAHULUAN}

IImu akuntansi sudah dapat diperoleh semenjak pendidikan di sekolah menengah yakni melalui jalur IImu Pengetahuan Sosial (SMU) atau secara khusus dengan memasuki sekolah ilmu kejuruan yakni di Sekolah Menengah Kejuruan Jurusan Akuntansi. Perbedaannya adalah untuk lulusan SMK dapat langsung masuk ke dunia Industri sedangkan untuk yang lulusan SMU IPS harus masuk ke perguruan tinggi.

Pendidikan akuntansi selama ini yang diberikan di SMU atau SMK masih menggunakan asumsi bahwa posisi transaksi dalam posisi dokumen lengkap. Artinya dokumen pendukung tekah sempurna dihasilkan dari sebuah sistem akuntansi yang terselenggara dengan baik. Hal ini dapat kita lihat dari buku-buku yang digunakan. Buku-buku tersebut menggunakan narasi lengkap dari sebuah transaksi atau bahkan untuk level praktikum di SMK, bukti transaksi sudah tersedia dengan jelas. Tanggal, tujuan dan peruntukan transaksi sudah di ketahui dengan melihat misalnya dari dokumen penjualan yang dilampirkan dalam buku praktikum.

Para siswa didik dalam posisi untuk mengikuti prosedur baku. Bahwa akuntansi dimulai dari proses kejadian, kemudian dituangkan dalam bukti transaksi, di analisa dan kemudian 
dicatat dalam bentuk jurnal. Setelah itu jurnal diklasifikasi ke dalam masing-masing buku besarnya untuk kemudian nantinya di ringkas dalam bentuk trial balance dan menyusunnya menjadi sebuah laporan laba rugi, neraca, laporan perubahan modal dan arus kas.

Selain itu pendidikan akuntansi juga dilaksanakan secara terpisah dengan perpajakan. Akuntansi dipelajari dalam mata pelajaran tersendiri dan perpajakan juga dalam mata pelajaran tersendiri. Perpajakan juga hanya di batasi pada masalah PPh pasal 21 sehubungan dengan karyawan yang tidak berhubungan langsung dengan pajak sehubungan dengan laporan keuangan yang disusun. Selain itu pajak juga memiliki cakupan yang sangat luas yang merupakan standar untuk bisa berpraktik dalam dunia industri. Jika hanya mempelajari PPh 21 tentu saja tidak cukup.

Gencarnya pemerintah untuk membangun infrastruktur secara masif selama empat tahun terakhir adalah dalam rangka mendukung aksesibilitas dan konektifitas manusia dan juga memfasilitasi dunia industri. Namun hal tersebut tidak akan bermakna apa-apa jika tidak di dukung oleh sumber daya manusianya. Maka selanjutnya adalah mengembangkan sumberdaya yang mumpuni untuk mendukung dunia industri yang semakin berkembang dengan segala kompetensi yang dibutuhkan.

Saat ini dunia industri sudah memasuki era Industri 4.0 lulusan dari penyelenggara pendidikan harus memiliki kompetensi yang berbasis teknologi agar mampu memiliki daya saing dan mengikuti perkembangan zaman. Industri yang sedang berjalan di dalam negeri, semestinya dapat dijalankan dan dikerjakan oleh tenaga kerja lokal dengan cara meningkatkan kapasitas mereka. Sehingga mereka tidak sekedar menempati jabatan rendah.

Saat ini terdapat kegelisahan di lingkungan pendidikan kejuruan. Tujuan dari pendidikan adalah untuk menyiapkan secara spesifik untuk industri tertentu. Telah ada kebijakan untuk lebih banyak pendidikan kejuruan daripada sekolah menengah umum dengan perbandingan 70:30. Dampakanya diharapkan hal ini akan mengurangi pengangguran dengan cara lulusan SMK dapat langsung bekerja tanpa harus melalui jenjang perguruan tinggi. Namun kenyataannya justru lulusan SMK menjadi penyumbang pengangguran dimana 52\% lulusan SMK tidak terserap (Sutrisno, 2013:1). Hal ini dapat disebabkan oleh tidak adanya link and match antara pendidikan yang diberikan dengan kebutuhan kompetensi praktis di real dunia industrinya.

Dalam dunia praktis kita tidak akan selalu menemukan kondisi sebagaimana yang tertuang dalam buku teks. Lebih banyak, bahkan, kita menemukan kondisi yang sangat jauh dari yang 
ISSN : $2620-4665$ (print)

ISSN : 2620 - 4673 (online)

Website : http://jurnal.untan.ac.id/index.php/JPLP2KM

tertulis. Sebagai contoh, penyusunan laporan keuangan oleh dunia industri hanya dilakukan setelah akhir tahun atau setelah akhir tahun buku tidak bulan perbulan apalagi harian. Pelaporan bahkan lebih hanya untuk memenuhi kewajiban untuk melaporkan.

Data yang tersedia juga seadanya, hanya berupa buku kas, nota bon, faktur pajak, kwitansi-kwitansi, rekening koran dan SPT tahunan. Data-data tersebut bahkan tidak terfiling dengan sempurna. Yang terparah kemudian adalah catatan yang berupa oret-oretan di kertas sehingga mutlak transaksi hanya tercatat di pihak ketiga yakni bank.

Dalam dunia praktis kita juga akan menjumpai bahwa tidak ada pemisahan antara transaksi pemiliki dengan transaksi perusahaan. Pertanyaan yang sering timbul kemudian adalah bagaimana meyusun laporan keuangan dalam kondisi serba terbatas. Jika kompetensi yang semata-mata diberikan saat ini di sekolah maka tentu saja keahlian ataupun keterampilan tersebut tidak akan mampu menjawab kebutuhan tersebut.

Teknologi informasi yang ada saat ini, jika kita tahu cara memanfaatkannya, dapat membantu kita setiap pekerjaan termasuk mengelola pencatatan akuntansi sampai dengan menghasilkan laporan keuangan. Kemampuan penggunaan teknologi informasi saat ini tidak dapat hindari, hampir setiap elemen kehidupan kita bersentuhan dengan teknologi. Dalam kaitannya dengan pelaporan otoritas pajak adalah instansi yang sedang gencar-gencarnya meminta wajib pajak untuk menyampaikan pelaporan secara elektronik melalui e-SPT bahkan berbasis web melalui media e-filing. Alasannya adalah bahwa dengan pelaporan secara eklektronik maka data akan lebih mudah dikelola misalnya pada saat pencarian, melakukan pengelompokan, analisa data termasuk menghemat ruang penyimpanan dan yang pasti ramah lingkungan karena tidak perlu lagi menggunakan kertas. Dari sisi Wajib Pajak (WP), WP dapat melakukan pelaporan dimanapun posisinya berada sepanjang termasuk Wajib Pajak (WP).

Berdasarkan pemaparan di atas kami melihat bahwa untuk meningkatkan kompetensi siswa lulusan sekolah menengah dapat dilakukan melalui peningkatan kompetensi guru yang mengajar. Kami berkeyakinan bahwa guru yang memiliki kompetensi akan mengajarkannya kepada siswa Oleh karena itu kami mengusulkan program pengabdian masyarakat "Pelatihan Penyusunan Laporan Keuangan dan Pajak Entitas Yang Tidak Menyelenggarakan Sistem Akuntansi Bagi Guru SMK Dan SMA Pengajar Akuntansi di Kota Pontianak". 


\section{METODE}

Khalayak Sasaran dari kegiatan ini adalah guru SMK Akuntansi dan SMA yang mengajar akuntansi di sekolah menengah di Kota Pontianak. Masing-masing sekolah akan diminta perwakilan masing masing 2 guru hingga terpenuhi 30 peserta. Sekolah SMK dan SMA di kota Pontianak tersebar di Pontianak Kota, Pontianak Selatan Pontianak Timur, dan Pontianak Tenggara Pontianak Barat dan Pontianak Utara. Terdapat 46 sekolah SMA dan 12 SMK yang memiliki jurusan akuntansi.

Berdasarkan undang-undang No. 20 Tahun 2013 Pasal 18 Ayat 3 bahwa yang dimaksud sebagai SMK adalah bentuk pendidikan formal yang menyelenggarakan pendidikan kejuruan pada jenjang pendidikan menengah sebagai lanjutan dari SMP/MTs atau bentuk lain yang sederajat atau lanjutan dari hasil belajar yang diakui sama/setara SMP/MTS. Lebih lanjut dalam pasal 15 disebutkan bahwa Pendidikan kejuruan adalah merupakan pendidikan menengah yang mempersiapkan peserta didik terutama untuk bekerja dalam bidang tertentu. Sedangkan yang dimaksud dengan SMU adalah bentuk satuan pendidikan menengah yang menyelenggarakan program pendidikan tiga tahun setelah sekolah lanjutan tingkat pertama (SLTP).

\section{HASIL DAN PEMBAHASAN}

\section{Tahap persiapan}

\section{a. Melakukan undangan/seleksi peserta.}

Kerjasama dengan Dinas Pendidikan dan Kebudayaan Provinsi Kalimantan Barat. Kami menyurati Dinas untuk membantu memfasilitasi kami mendapatkan peserta yang relevan. Pertimbangannya adalah Dinas tentulah memiliki database guru SMA dan SMK pengajar akuntansi di Kota Pontianak.

\section{b. Undangan peserta \& Perwakilan Dinas}

Setelah kami mendapatkan daftar calon peserta pelatihan, kami menyebarkan undangan ke alamat masing-masing peserta berdasarkan data yang kami dapatkan dari dinas. Kami juga mengundang perwakilan dari Dinas dan Direktorat Jendral Pajak untuk ikut serta dalam kegiatan tersebut sebagai stakeholders dari kalangan pemerintah. 
ISSN : $2620-4665$ (print)

ISSN : $2620-4673$ (online)

Website : http://jurnal.untan.ac.id/index.php/JPLP2KM

\section{c. Menyiapkan bahan pelatihan.}

Menyusun bahan pelatihan berupa penyiapan simulasi kasus, pengetikan, penjilidan dan pengujian yang dilaksanakan secara tim. Bahan disiapkan dengan menyesuaikan karakteristik peserta yang berdasarkan biodata umumnya adalah dari kalangan guru pengajar akuntansi dengan ilustrasi kasus perusahaan dan SPT WP OP 1770.

\section{d. Arangment tempat kegiatan}

Kegiatan ini meliputi permohonan peminjaman ruang Accounting Hall gedung jurusan akuntansi polnep ke bagian kerumahtanggaan karena berdasarkan pertimbangan tempat inilah yang paling representative. Selain itu juga disiapkan baliho, sound system, dan tata letak ruangan yang memudahkan untuk kegiatan dengan format seminar dan pelatihan.

\section{e. Persiapan aplikasi dan komputer untuk pelatihan.}

Instalasi aplikasi pajak dilakukan dilaptop jurusan akuntansi polnep. Aplikasi yang digunakan adalah aplikasi excel dan aplikasi e-SPT. Pertimbagannya adalah aplikasi ini sudah tersedia disetiap laptop, cukup banyak pemakainya, dan mudah digunakan. Karena di laptop yang akan digunakan belum memiliki aplikasi e-SPT maka kami tentu saja harus menyiapkan instalasinya. Kegiatan ini sepenuhnya dapat terlaksana dengan pelibatan mahasiswa.

\section{f. Test case}

Test case adalah kegiatan menguji coba modul/bahan pelatihan ke dalam sistem aplikasi untuk memastikan tidak ada kendala teknis pada saat nanti di gunakan saat pelatihan.

\section{Tahap Seminar dan Pelatiha Teknis}

Berikut adalah rundown acara yang telah dilaksanakan dalam format seminar \& pelatihan yang terlaksana dari tanggal 23 s.d. 24 Oktober 2018 bertempat di ruang Accounting Hall Gedung jurusan Akuntansi Politeknik Negeri Pontianak. 
JURNAL PENGABDI

APRIL 2019, Volume 2 Nomor 1

\begin{tabular}{|c|c|c|}
\hline Jam (WIB) & Kegiatan & PIC \\
\hline \multicolumn{3}{|c|}{ Hari Pertama: 23 Oktober 2018} \\
\hline 08.00-09.00 & $\begin{aligned} & \text { Pembukaan } \\
- & \text { Sambutan Ketua Panitia } \\
- & \text { Sambutan Kepala Dinas Pendidikan } \\
& \text { Provinsi Kalbar } \\
\text { Doa } & \end{aligned}$ & Panitia \\
\hline 09.00-09.15 & Coffe Break & \\
\hline $09.15-10.00$ & $\begin{array}{l}\text { Gambaran Umum Praktek Akuntansi di UMKM } \\
\text { dan Pendekatan Belajar di Sekolah Menengah } \\
{ }^{1} \text { Entitas yang umumnya tidak } \\
\text { Menyelenggarakan SIA }\end{array}$ & Tim Akuntansi PPM Polnep \\
\hline 10.15-12.00 & $\begin{array}{l}\text { - Kebutuhan Skill dan pengetahuan pajak di } \\
\text { UMKM - PP } 23 \text { Tahun } 2018\end{array}$ & DJP \\
\hline $12.00-13.00$ & Ishoma & \\
\hline 13.00.15.00 & $\begin{array}{l}\text { Praktik - Penyusunan Laporan Entitas Yang tak } \\
\text { Menyelenggakan SIA }\end{array}$ & Tim Akuntansi PPM Polnep \\
\hline $15.00-15.30$ & Coffe Break & Tim Akuntansi PPM Polnep \\
\hline $15.30-16.30$ & $\begin{array}{l}\text { Praktik - Penyusunan Laporan Entitas Yang tak } \\
\text { Menyelenggakan SIA }\end{array}$ & Tim Akuntansi PPM Polnep \\
\hline \multicolumn{3}{|c|}{ Hari Kedua: 24 Oktober 2018} \\
\hline $08.00-11.00$ & $\begin{array}{ll}\text { - } & \text { Pengenalan e-SPT tahunan WP OP } \\
\text { - } & \text { Praktik Penyusunan Laporan Pajak - e } \\
& \text { SPT }\end{array}$ & Tim Akuntansi PPM Polnep \\
\hline $11.00-11.15$ & Coffe Break & Panitia \\
\hline $11.15-12.00$ & Praktik Penyusunan Laporan Pajak - e SPT & Tim Akuntansi PPM Polnep \\
\hline $12.00-13.00$ & Ishoma & Panitia \\
\hline $13.15-15.00$ & Praktik Penyusunan Laporan Pajak - e SPT & Tim Akuntansi PPM Polnep \\
\hline $15.00-15.15$ & Coffe Break & Panitia \\
\hline $15.15-16.00$ & Penutupan & Panitia \\
\hline
\end{tabular}

Tabel 1 : Rundown Acara 
ISSN : $2620-4665$ (print)

ISSN : 2620 - 4673 (online)

Website : http://jurnal.untan.ac.id/index.php/JPLP2KM

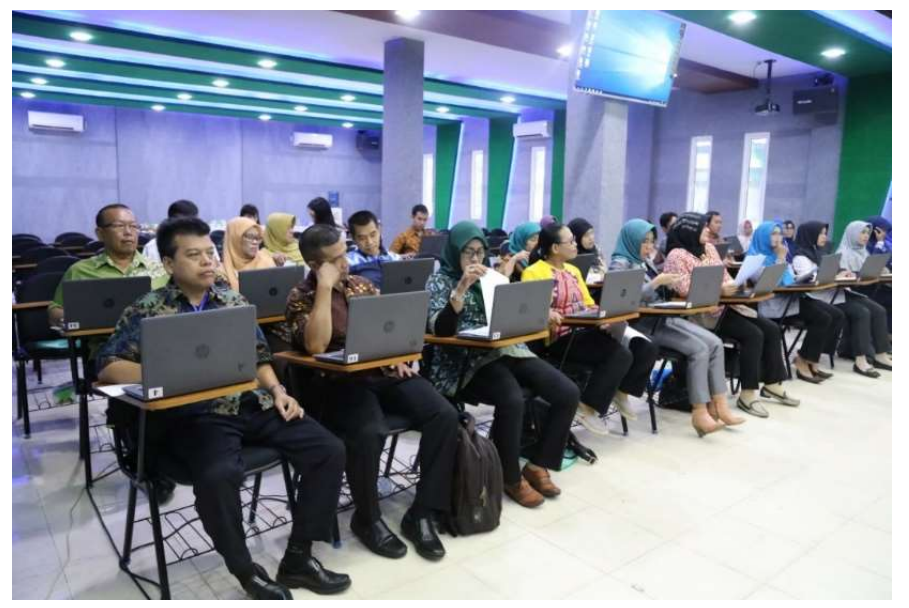

Gambar 1. Sesi Praktek Perpajakan

Jumlah peserta yang mengikuti kegiatan adalah 32 peserta yang berasal dari beragam sekolah. Para guru pengajar akuntansi yang mengikuti kegiatan ini tersebar di kota Pontianak yakni dari SMKN 1, SMKN 7, SMK PGRI, SMAN 7, SMAN 10, SMAN 9, SMAN 6, SMAN 1, SMAN 2, SMAN 3, SMK IMMANUEL, SMAN 4 , SMAN 8, SMK LKIA, SMK YPK, SMK SANTA MARIA, dan SMKN 3.

\section{Tahap Evaluasi}

Setelah kegiatan selesai, kami melakukan evaluasi kegiatan pelatihan dengan menanyakan respon peserta terhadap kegiatan pelatihan. Berikut adalah ringkasan hasil evaluasi kegiatan dari 32 peserta. 


\begin{tabular}{|c|c|c|c|c|c|}
\hline Item Pertanyaan & $\begin{array}{l}\text { Tidak } \\
\text { Baik }\end{array}$ & $\begin{array}{l}\text { Kurang } \\
\text { Baik }\end{array}$ & Cukup & Baik & $\begin{array}{l}\text { Sangat } \\
\text { Baik }\end{array}$ \\
\hline \multicolumn{6}{|c|}{$\begin{array}{l}\text { 1. Menurut anda, bagaimana kualitas sarana dan fasilitas pendukung kegiatan seminar } \\
\text { dan pelatihan. }\end{array}$} \\
\hline Lokasi kegiatan & $0 \%$ & $0 \%$ & $0 \%$ & $69 \%$ & $31 \%$ \\
\hline Pengaturan ruangan & $0 \%$ & $0 \%$ & $9 \%$ & $69 \%$ & $22 \%$ \\
\hline Makanan & $0 \%$ & $0 \%$ & $0 \%$ & $75 \%$ & $25 \%$ \\
\hline \multicolumn{6}{|c|}{ 2. $\quad$ Bagaimana pemilihan materi dan pembahasan dalam sesi-sesi berikut: } \\
\hline $\begin{array}{l}\text { Gambaran Umum praktik akuntansi } \\
\text { UMKM di sekolah menengah }\end{array}$ & $0 \%$ & $0 \%$ & $0 \%$ & $78 \%$ & $22 \%$ \\
\hline $\begin{array}{l}\text { Kebutuhan skill dan pengetahuan } \\
\text { pajak di UMKM (pp No. } 23 \text { Tahun } \\
2018\end{array}$ & $0 \%$ & $0 \%$ & $0 \%$ & $78 \%$ & $22 \%$ \\
\hline $\begin{array}{lr}\text { Praktik - penyusunan } & \text { laporan } \\
\text { entitas yang } & \text { tidak } \\
\text { menyelenggarakan } & \text { Sistem } \\
\text { akuntansi } & \end{array}$ & $0 \%$ & $0 \%$ & $16 \%$ & $53 \%$ & $31 \%$ \\
\hline $\begin{array}{l}\text { Praktik Penyusunan Laporan Pajak } \\
\text { - e SPT }\end{array}$ & $0 \%$ & $0 \%$ & $16 \%$ & $59 \%$ & $25 \%$ \\
\hline Keseluruhan & $0 \%$ & $0 \%$ & $6 \%$ & $69 \%$ & $25 \%$ \\
\hline
\end{tabular}

Tabel 2: Evaluasi Kegiatan

Kami juga memberikan pertanyaan terbuka mengenai apa yang mereka sukai di Seminar \& Pelatihan ini? Jawaban mereka kami kelompokkan dalam lima kategori:

1. Praktik Langsung Bukan Sekedar Teori

2. Narasumber menyampaikan materi jelas dan mudah dipahami

3. Tutor yang friendly (Sopan \& Mudah di Pahami)

4. Lain-lain (seperti topik perpajakannya, tempat kegiatan dll)

5. Tidak Menjawab

Diagram Pie di bawah ini memberikan gambaran mengenai respon mereka.

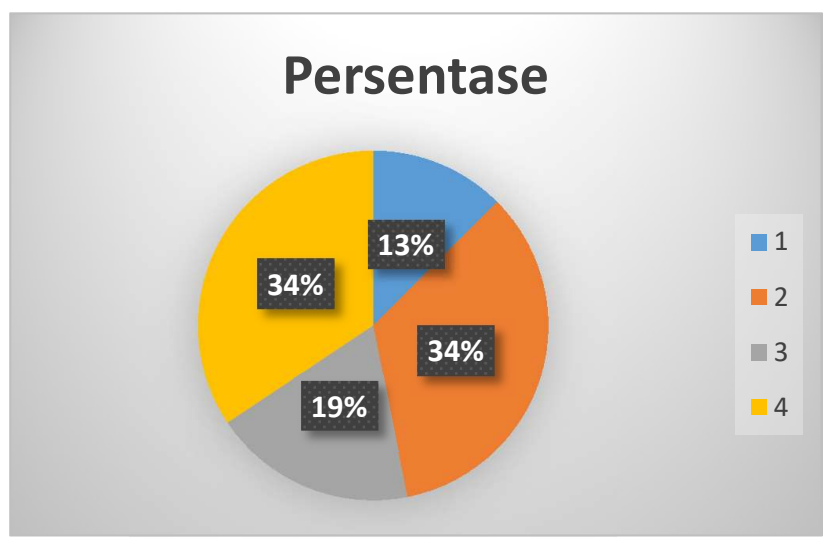

Gambar 1. Survei Respon Atas Seminar \& Pelatihan 
ISSN : $2620-4665$ (print)

ISSN : 2620 - 4673 (online)

Website : http://jurnal.untan.ac.id/index.php/JPLP2KM

Dan apa yang mereka harapkan dan usulkan untuk kegiatan Seminar dan Pelatihan yang akan datang? $34 \%$ menjawab agar kegiatan seperti dilaksanakan kembali. 19\% mengatakan agar kegiatan ini ada penambahan waktu, 13\% mengatakan agar kegiatan ini ada tindak lanjutnya seperti pendampingan. Dan sisanya 34 persen menyatakan saran dan perbaikan seperti kualitas cetakan modul yang lebih baik, kemudian ada juga yang menyarankan agar dipraktekan langsung kepada peserta.

\section{SIMPULAN}

Pendidikan akuntansi selama ini yang diberikan di SMU atau SMK masih menggunakan asumsi bahwa posisi transaksi dalam posisi dokumen lengkap. Artinya dokumen pendudukung tekah sempurna dihasilkan dari sebuah sistem akuntansi yang terselenggara dengan baik. Hal ini dapat kita lihat dari buku-buku yang digunakan. Buku-buku tersebut menggunakan narasi lengkap dari sebuah transaksi atau bahkan untuk level praktikum di SMK, bukti transaksi sudah tersedia dengan jelas. Tanggal, tujuan dan peruntukan transaksi sudah di ketahui dengan melihat misalnya dari dokumen penjualan yang dilampirkan dalam buku praktikum.

Di sisi lain, gencarnya pemerintah untuk membangun infrastruktur secara massif selama empat tahun terakhir adalah dalam rangka mendukung aksesibilitas dan konektifitas manusia dan juga memfasilitasi dunia industri. Namun hal tersebut tidak akan bermakna apa-apa jika tidak di dukung oleh sumber daya manusianya. Maka selanjutnya adalah mengembangkan sumberdaya yang mumpuni untuk mendukung dunia industri yang semakin berkembang dengan segala kompetensi yang dibutuhkan.

Berdasarkan pemaparan di atas kami melihat bahwa untuk meningkatkan kompetensi siswa lulusan sekolah menengah dapat dilakukan melalui peningkatan kompetensi guru yang mengajar. Kami berkeyakinan bahwa guru yang memiliki kompetensi akan mengajarkannya kepada siswa Oleh karena itu kami mengusulkan program pengabdian masyarakat "Pelatihan Penyusunan Laporan Keuangan dan Pajak Entitas Yang Tidak Menyelenggarakan Sistem Akuntansi Bagi Guru Smk Dan Sma Pengajar Akuntansi di Kota Pontianak".

Kegiatan ini tidak hanya penting bagi para guru tapi juga bagi POLNEP dan juga pemerintah. Bagi para guru mereka akan memiliki kompetensi baru yang lebih mumpuni dan aplikatif bagi siswa mereka. Bagi POLNEP hal ini merupakan sarana untuk menyalurkan kegiatan Tri Dharma Perguruan tinggi Sementara bagi pemerintah, kegiatan ini akan sangat 
membantu program pemerintah dalam mewujudkan terciptanya sumberdaya manusia yang siap kerja di dunia industri agar tidak terjadi pengangguran yang terlalu lebar.

\section{DAFTAR PUSTAKA}

Mahmudi, Ali 2005 Sistem Informasi Akuntansi Perusahaan Accurate-3, Grasindo Jakarta

Ramadhan, Noval 2014 Komputer Akuntansi dan Manfaatnya Bagi Alam Pekerjaan, Zahir Accunting, Jakarta

Suwardjono, Akuntansi Pengantar 1: proses penciptaan data, pendekatan sistem, Yogyakarta BPFE, 2011.

Trianto, Arvin \& Bastian, Saputra. 2012. MYOB versi 18. Penyelesaian Kasus Pendekatan Bukti Transaksi. Penerbit Andi. Yogyakarta.

I Made Mega. 2012. Mengaplikasikan Komputer Akuntansi dengan MYOB versi 18. Inti Prima. Jakarta.

Tampubolon, Karianton 2016 Akuntansi Perpajakan dan Cara Menghadapi Pemeriksaan Pajak, Indeks, Jakarta

Weygandt, Jerry J.; Donald E. Kieso; and Paul D. Kimmel, Accounting Principles. New York: John Willey \& Sons, 2007. 